\title{
Laparoscopic repair of wound defects in the elderly: our experience of 5 years
}

\author{
Alessia G Ferrarese ${ }^{*}$, Valter Martino ${ }^{\dagger}$, Stefano Enrico $^{\dagger}$, Alessandro Falcone $^{\dagger}$, Silvia Catalano ${ }^{\dagger}$, Enrico Gibin $^{\dagger}$, \\ Silvia Marola ${ }^{\dagger}$, Alessandra Surace $^{\dagger}$, Mario Solej $^{\dagger}$ \\ From 26th National Congress of the Italian Society of Geriatric Surgery \\ Naples, Italy. 19-22 June 2013
}

\begin{abstract}
Background: Laparoscopic approach for wound defects is a procedure that aims to reduce surgical aggressiveness against the abdominal wall by using minimal incisions and dedicated instruments.

Methods: We report our experience about clinical outcome of elderly patients undergoing laparoscopic repair for incisional hernias (Group I) and primary inguinal hernias (Group II) from June 2007 to September 2012.

We analyzed preoperative and postoperative data for the laparoscopic approach in the elderly.

Results and discussion: In our experience there was no significant difference in laparoscopic procedure between normalweight and overweight patients.

Conclusions: Laparoscopic repair for primary inguinal hernias and incisional ventral hernias with transabdominal placement of composite mesh in the elderly achieves excellent results with lower morbidity in comparison with open surgical approaches.
\end{abstract}

\section{Background}

Laparoscopic approach of wound defects is a procedure that aims to reduce surgical aggressiveness against the abdominal wall by using minimal incisions and dedicated instruments. The procedure also aims to decrease total hospital stay and morbility [1-3].

In the literature there are few study about wound defects in elderly [4-9].

We report our experience about clinical outcome of elderly patients undergoing laparoscopic repair for incisional hernias (Group I) and primary inguinal hernias (Group II). Aim of this study is to assess the safety of laparoscopic wound defects repair in elderly patients; moreover the study wants to test our technique efficacy after 5 years of experience.

\footnotetext{
* Correspondence: alessia.ferrarese@gmail.com

† Contributed equally

University of Turin, Department of Oncology, School of Medicine, Teaching Hospital "San Luigi Gonzaga", Section of General Surgery, Orbassano, Turin, Italy
}

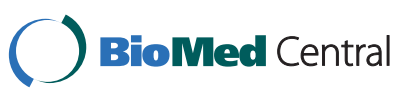

(C) 2013 Ferrarese et al; licensee BioMed Central Ltd. This is an open access article distributed under the terms of the Creative Commons Attribution License (http://creativecommons.org/licenses/by/2.0), which permits unrestricted use, distribution, and reproduction in any medium, provided the original work is properly cited.

\section{Methods}

From June 2007 to September 2012 we performed 63 laparoscopic wound defects repair in 52 elderly patients. Exclusion criteria were: anesthesiologic contraindication for laparoscopy, ASA IV score. We didn't exclude ASA III patients: in these patients we used abdominal pressure not superior to $10 \mathrm{mmHg}^{(1 \mathrm{VLC})}$. The sample was composed by 37 male and 15 female patients. We performed 21 surgical incisional hernia repair and 42 primary hernia repair. Of those, 17 were for incisional single defect hernias (24.5\% recurrence hernias), 4 for multiple defects (7,54\% recurrence hernias); 18 laparoscopic repairs were performer for unilateral inguinal hernias $(22,56 \%$ recurrence hernias), 16 for bilateral inguinal hernias $(30,08 \%$ recurrence hernias), 4 for umbilical hernias (1 recurrence hernias), 2 for epigastric and linea alba's hernias, and 2 for rectum diastasis.

Wound defects diagnosis based on objective and clinical aspects, physical examination and radiologic findings like US and CT. For this study we also considered: hernia defect size, recurrence rate and operative time. All procedure-related complications were evaluated. $42 \%$ of the 
patients were normalweight with a mean BMI of $25 \mathrm{~kg} /$ m2, $41 \% 25>$ BMI > 30 (overweight), 17\% BMI > 30 (obesity).

\section{Results and discussion}

There were no significant differences in laparoscopic procedure between normalweight and overweight elderly patients [1-3]. There were no conversions to open procedure. Mean operative time was 116 minutes (range: 50 - 325). We analyzed preoperative and postoperative data not finding any significant difficulty difference in the laparoscopic approach in the elderly [10-13]. In primary inguinal hernias, in $37,5 \%$ of cases we used not absorbable polypropylene mesh, in $42,5 \%$ tridimensional polyester-collagen composite mesh and in $20 \%$ lightweight multifilament partly absorbable mesh.

Meshes were fixed in $82.5 \%$ of cases with absorbable fixation device, in $5 \%$ with not absorbable device and in $12.5 \%$ with fibrin glue.

In ventral hernias we used in all cases a polyester double-face mesh and fixed with absorbable devices. There was no difference as far as concerns the elderly quality of life between different meshes or fixation methods.

We had 6 major complications (14,24\% - 2 chronic inguinal pain and 4 recurrences in inguinal hernias) $[18,13]$ and 5 minor complications $(11,90 \%-3$ seromas and 2 wound haematomas in ventral hernias) $[11,7,9]$. Mean hospital stay was 4,7 days (range: 1-18 days) in Group I and 1,2 days in Group II; all patients referred better quality of life after the procedure.

All procedures were performed by an expert surgeon or by a resident with an expert surgeon; there was no significant difference in intraoperative complications and operation time depending on the first operator.

\section{Conclusion}

Laparoscopic repair of primary inguinal hernias and incisional ventral hernias with transabdominal placement of composite mesh in the elderly achieves excellent results with lower morbidity in comparison with open surgical approaches. In our experience, adequate fixation of the mesh, mesh extension to cover the entire defect and standardization of the placement space between the sutures are crucial to the success [10-12].

Despite the retrospective analysis of our sample, the study showed that elderly patients can be operated with laparoscopic approach with the same advantages that would be obtained if operated with open technique $[13,14]$. The resident with an expert surgeon can obtain the same results of an expert surgeon as far as concerns outcomes and morbidity.

We consider surgery approach more difficult in the elderly in some cases [15] but we also considered laparoscopic approach is, in general, a safe and feasible technique in acute pathology [16] and a safe approach also in the elderly $[17,18]$. In our experience, laparoscopic repaire of wound defects is a good standard technique also in the elderly.

\section{Competing interests}

The authors declare that they have no competing interests.

\section{Authors' contributions}

AGF: conception and design, interpretration of data, given final approval of the version to be published.

VM: critical revision, interpretation of data, given final approval of the version to be published.

SE: conception and design, interpretration of data, given final approval of the version to be published.

AF: acquisition of data, drafting the manuscript, given final approval of the version to be published.

SC: acquisition of data, drafting the manuscript, given the final approval of the version to be published.

EG: acquisition of data, drafting the manuscript, given the final approval of the version to be published.

AS: critical revision, interpretation of data, given final approval of the version to be published.

MS: acquisition of data, drafting the manuscript, given final approval of the version to be published.

\section{Declarations}

Funding for this article came from personal funds.

This article has been published as part of BMC Surgery Volume 13 Supplement 2, 2013: Proceedings from the 26th National Congress of the Italian Society of Geriatric Surgery. The full contents of the supplement are available online at http://www.biomedcentral.com/bmcsurg/supplements/13/ S2

\section{Published: 8 October 2013}

\section{References}

1. Lee YK, lqbal A, Vitamvas M, McBride C, Thompson J, Oleynikov D: Is it safe to perform laparoscopic ventral hernia repair with mesh in elderly patients? Hernia 2008, 12:239-42.

2. Tessier DJ, Swain JM, Harold KL: Safety of laparoscopic ventral hernia repair in older adults. Hernia 2006, 10:53-7.

3. Bàllesta López C, Cid JA, Poves I, Bettónica C, Villegas L, Memon MA: Laparoscopic surgery in the elderly patient. Surg EndosC 2003, 17:333-7.

4. Mudge $M$, Hughes L: Incisional hernia: a 10 year prospective study of incidence and attitudes. Br J Surg 1985, 72:70-71.

5. Read R, Yoder G: Recent trends in the management of incisional herniation. Arch Surg 1989, 124:485-488.

6. Rosen M, Brody F, Ponsky J, et al: Recurrence after laparo-scopic ventral hernia repair: a five-year experience. Surg Endosc 2003, 17:123-128.

7. Berger D, Bientzle M, Muller A: Postoperative complications after laparoscopic incisional hernia repair: incidence and treat-ment. Surg Endosc 2002, 16:1720-1723.

8. Carbajo M, Martin del Olmo J, Blanco J, et al: Laparoscopic approach to incisional hernia: lessons learned from 270 patients over 8 years. Surg Endosc 2003, 17:118-122.

9. Tessier DJ, Swain JM, Harold KL: Safety of laparoscopic ventral hernia repair in older adults. Hernia 2006, 10:53-57.

10. Goodney P, Birkmeyer C, Birkmeyer J: Short-term outcomes of laparoscopic and open ventral hernia repair: a meta-analysis. Arch Surg 2002, 137:1161-1165.

11. Heniford B, Park A, Ramshaw B, Voeller G: Laparoscopic repair of ventral hernias: nine years' experience with 850 con-secutive hernias. Ann Surg 2003, 238:391-399.

12. Raftopoulos I, Vanuno D, Khorsand J, Ninos J, Kourakilis G, Lasky P: Outcome of laparoscopic ventral hernia repair in cor-relation with obesity, type of hernia, and hernia size. J Laparoen-dosc Adv Surg Tech 2002, 12:425-429.

13. Blount $A L$, Craft $R O$, Harold $K L$ : Safety of laparoscopic ventral hernia repair in octogenarians. JSLS 2009, 13:323-6. 
14. Carbonell A, Harold K, Mahmutovic A, et al: Local injection for the treatment of suture site pain after laparoscopic ventral hernia repair. Am Surg 2003, 69:688-691.

15. Ferrarese A, Martino V, Falcone A, Solej M, Destefano I: Perforated duodenal diverticulum: case report and short review of the literature., su Chirurgia.

16. Solej M, Martino V, Mao P, Enrico S, Rosa R, Fornari M, Destefano I, Ferrarese AG, Gibin E, Bindi F, Falcone A, Ala U, Nano M: Early versus delayed laparoscopic cholecystectomy for acute cholecystitis. Minerva Chirurgica 2012, 67(5):381-387.

17. Ferrarese A, Martino V, Nano M: Elective and emergency laparoscopic cholecystectomy in the elderly: early or delayed approach. BMC Geriatrics 2011, 11(Suppl 1):A14.

18. Ferrarese A, Martino V, Nano M: Wound defects in the elderly: our experience. BMC Geriatrics 2011, 11(Suppl 1):A15.

doi:10.1186/1471-2482-13-S2-S23

Cite this article as: Ferrarese et al:: Laparoscopic repair of wound defects in the elderly: our experience of 5 years. BMC Surgery 2013 13(Suppl 2):S23.

\section{Submit your next manuscript to BioMed Central} and take full advantage of:

- Convenient online submission

- Thorough peer review

- No space constraints or color figure charges

- Immediate publication on acceptance

- Inclusion in PubMed, CAS, Scopus and Google Scholar

- Research which is freely available for redistribution

Submit your manuscript at www.biomedcentral.com/submit 